\title{
Correction to: Overexpression of Shrm4 promotes proliferation and differentiation of neural stem cells through activation of GABA signaling pathway
}

\author{
Runhui Tian ${ }^{1} \cdot$ Kaimin $\mathrm{Guo}^{2} \cdot \mathrm{Bo} \mathrm{Wu}^{3} \cdot$ Hongbo Wang ${ }^{4}$ (I)
}

Published online: 24 June 2020

○) Springer Science+Business Media, LLC, part of Springer Nature 2020

\section{Correction to: \\ Molecular and Cellular Biochemistry (2020) 463:115-126 \\ https://doi.org/10.1007/s11010-019-03634-4}

The original publication of the article includes an error in Fig. 2. The correct version of the Fig. 2 is provided in this correction.

The original article can be found online at https://doi.org/10.1007/ s11010-019-03634-4.

Hongbo Wang

wanghongbo@jlu.edu.cn

1 Department of Psychology, The First Hospital of Jilin

University, Changchun 130021, People's Republic of China

2 Department of Andrology, The First Hospital of Jilin

University, Changchun 130021, People's Republic of China

3 Department of Psychology, The Sixth People's

Hospital of Changchun, Changchun 130000,

People's Republic of China

4 Department of Pediatric Respiratory Disease,

The First Hospital of Jilin University,

No. 71 Xinmin Street, Changchun 130021, Jilin Province,

People's Republic of China 

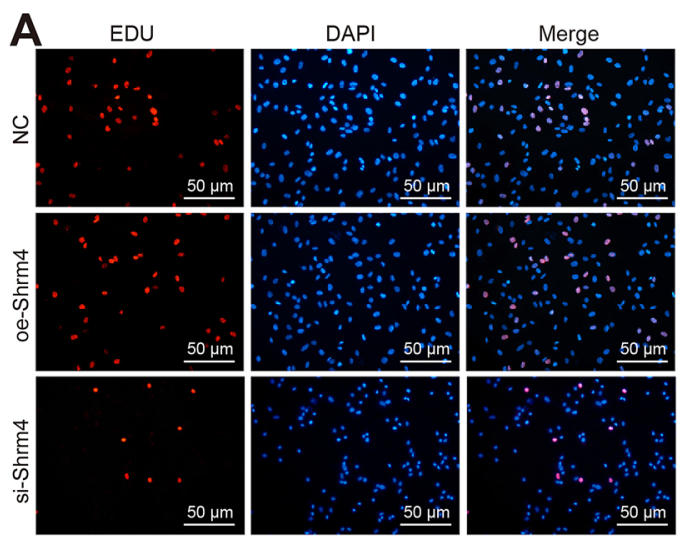

B

C
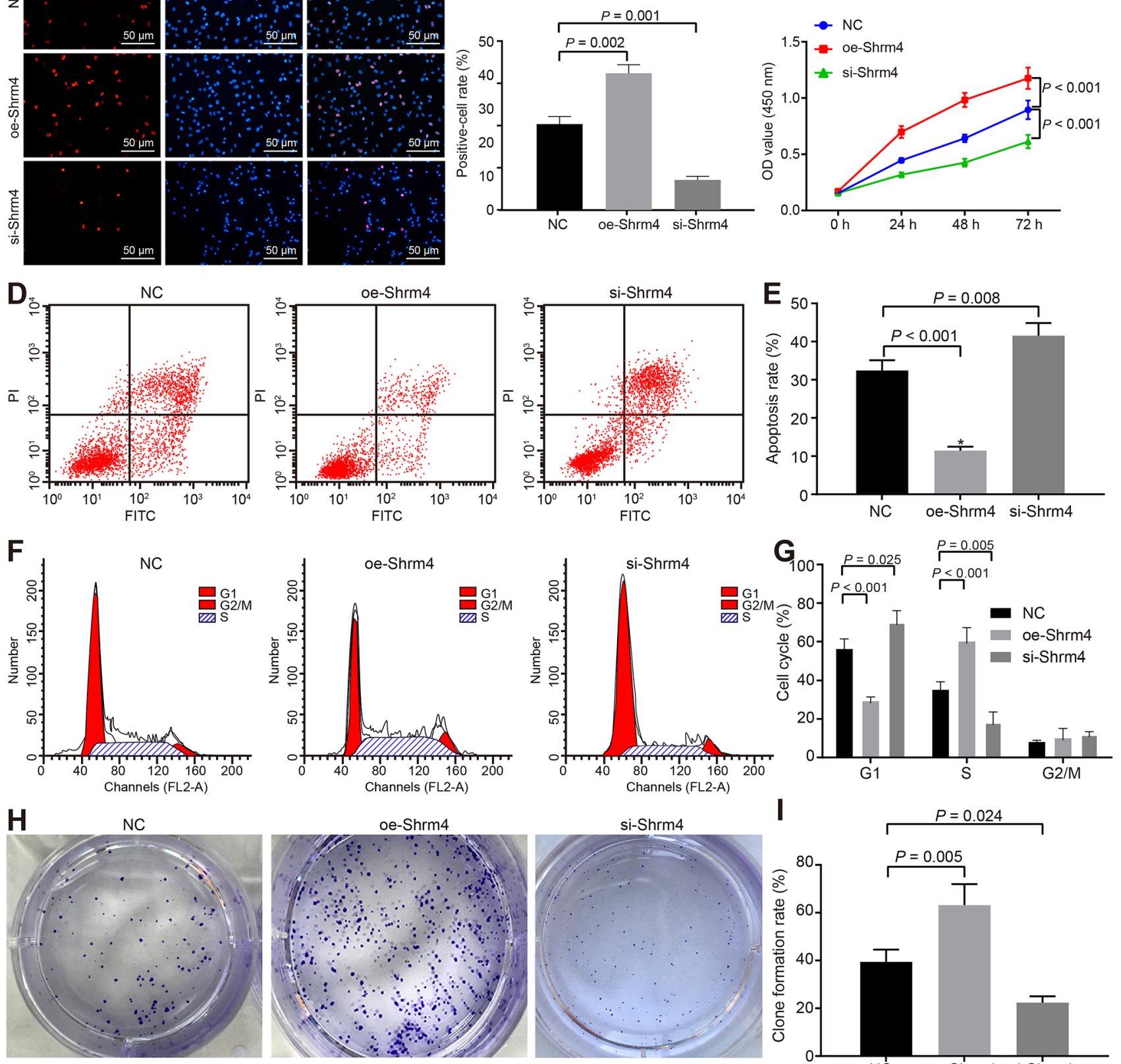

si-Shrm4
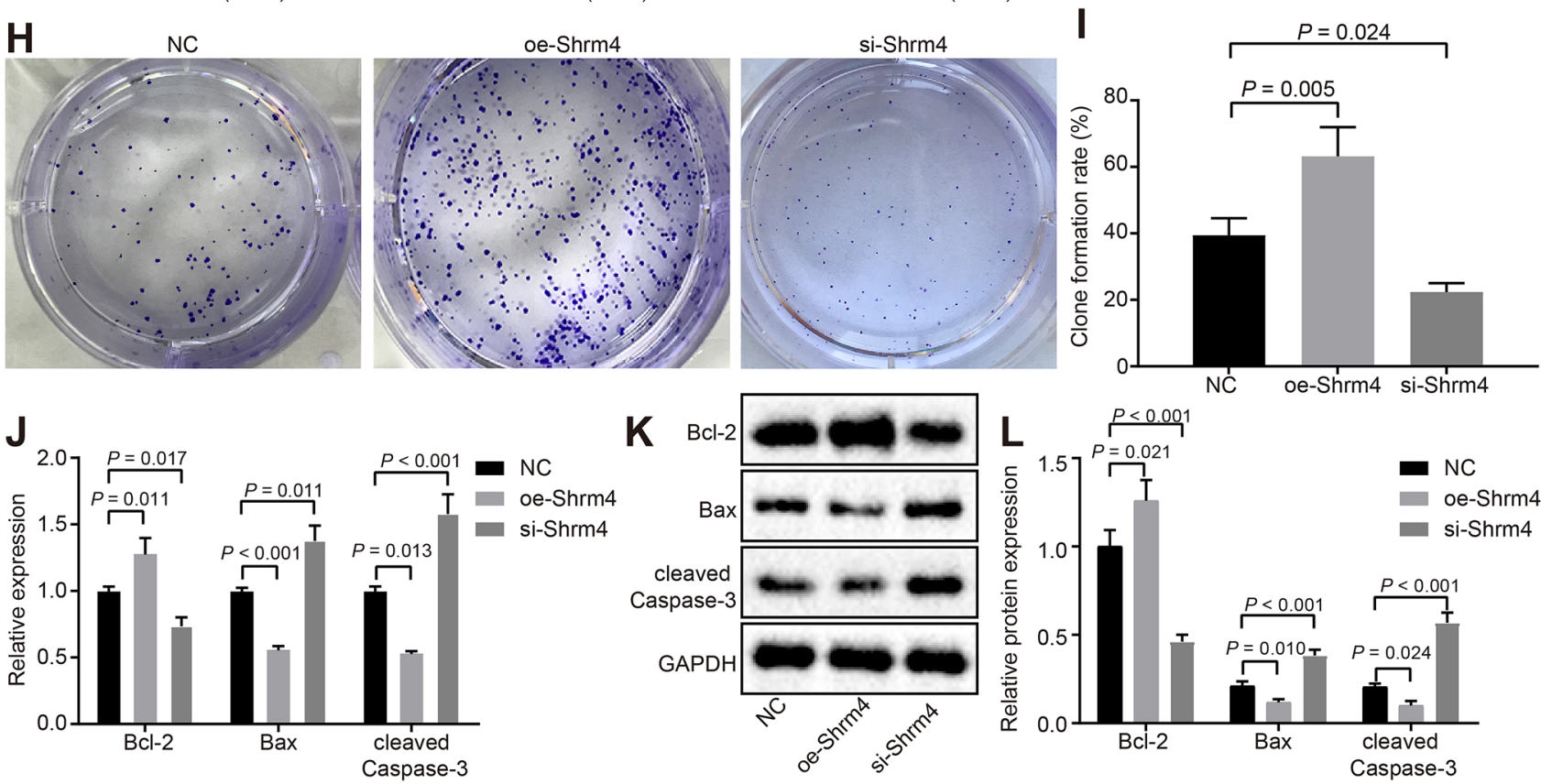
४Fig. 2 Shrm4 stimulates the proliferation of neural stem cells. a, b Positive cell rate of EdU-stained cells in each group; c cell viability detected by CCK-8 assay; $\mathbf{d}$, e apoptosis rate of cells in each group measured by flow cytometry; $\mathbf{f}, \mathbf{g}$, cell cycle distribution in different phases measured by flow cytometry; $\mathbf{h}, \mathbf{i}$, colony formation rate of cell in each group; $\mathbf{j}$ mRNA expression of cell proliferation-related gene in each group; $\mathbf{k}$ protein bands of cell proliferation-associated factors in each group; $\mathbf{l}$ protein expression of cell proliferation-related factors in each group; ${ }^{*} p<0.05$ versus the NC group; data between two groups were compared using the $t$ test for statistical analysis, and data at different time points were compared using repeated measures analysis of variance for statistical analysis; $n=3$. Brdu 5-bromozodoxyuridine, $C C K-8$ Cell Counting Kit- $8, N C$ negative control
Publisher's Note Springer Nature remains neutral with regard to jurisdictional claims in published maps and institutional affiliations. 